\title{
Involvement of Artificial Intelligence in Modern Society
}

\author{
Gregor Jagodič \\ International School for Social and Business Studies, Slovenia \\ gregor.jagodic@mfdps.si
}

\author{
Miloš Šinkovec \\ International School for Social and Business Studies, Slovenia \\ milossinkovec@gmail.com
}

\begin{abstract}
Purpose: We live in a time where technology and artificial intelligence are heavily embedded in our lives, so we need to use both intelligently. Some people fear it, while others try to exploit it to realise their potential by creating jobs, transforming industries, providing education, promoting advances in healthcare, space technology, science, etc.
\end{abstract}

Study design/methodology/approach: The study is based on a review of scientific literature in artificial intelligence, globalisation, economy and ethics. From that arise the question if we are ready for radical change.

Findings: The emergence of new professions will require a societal strategy to retrain employees and define which jobs will be unnecessary. The critical question is who will take responsibility for changes, that unemployment does not increase due to new technologies.

Originality/value: With the right approach, artificial intelligence can help and enable man, as an intelligent being, to devote himself to the more demanding tasks in the future.

\section{Introduction}

Artificial Intelligence (AI) is a set of systems that independently demonstrate intelligent behaviour to achieve specific objectives by analysing their environment and taking action. AI systems can be fully software-based and work in a virtual world, for example, voice assistants, image analysis software, search engines, speech and facial recognition systems. On the other hand, they can also be embedded in hardware, for example, in advanced robots, autonomous cars, drones or Internet applications. Deep learning has brought about AI reversal by dramatic performance improvements in image or speech recognition and machine translation tasks. Remarkable progress in these technologies has been made using large amounts of data collected in large databases and unprecedented computing capabilities (AI for Europe 2018, p. 11).

The breakthrough and launch of AI were carried out in the mid-20th century by British logic and computer pioneer Alan Mathison Turing. Turing's design is now known as the Turing Machine. Nowadays, all modern computers are universal Turing machines. (Alan Turing and the beginning of AI, n.d.).

In his AI study, Fox (2019, p. 37) states that intelligence is defined in traditional disciplines such as psychology and philosophy. However, today we link intelligence with cognitive science, which combines psychology and AI with philosophy, neuroscience, linguistics, etc. Cognitive science is an interdisciplinary scientific study of the mind and its processes. It explores human mental functions, such as reasoning, problem-solving, decision-making, and planning. The author says most of us would agree to be a model of intelligent action, whether artificial or natural.

The study focuses on theoretical starting points and is based on a literature review on AI's integration into society. The compilation method summarised and quoted the authors' theoretical starting points. The article aims to demonstrate the impact of AI and modern 
technologies in society on work and employment. By researching AI, we want to bring it closer to focusing on ethical guidelines and human-intelligence interactions and the need for education for future professions.

Based on the literature, we set two research questions:

- RQ1: How to reduce unemployment due to the spread of AI in society.

- RQ2: Who will take responsibility for the changes to make AI trustworthy.

\section{Artificial intelligence in the global world}

The basis of today's technological advances, generated and promoted in particular by the everfaster development of modern technology, hardware and software and the computer and information business models are based on previous inventions such as the steam machine, the typewriter, the telephone, electricity (Raiz Mir, Majed Qadri, and Mahnaz Hassan, 2014, p. 608). If Europe is to take full advantage of emerging innovation, it must consider several strategic factors. It needs to focus on the future, not the past. European policymakers should also pay attention to specific components of the foundations of reducing the attractiveness of the European Union as a destination for foreign investment in information communication technology (Atkinson and Ezell, 2019). The consequences of a small handful of countries controlling top-notch AI in the future can be enormous. Technologically advanced countries could become carriers of AI and ensure that essential resources are allocated in the long term (Wagner, 2018).

All countries welcome AI trends. AI is present everywhere, focusing on developed and underdeveloped countries and competing for supremacy in this area. China has ambitions to become a global superpower in the field of AI. China has announced that it will become a leader in AI by 2030, investing 150 billion USD. The goal is perfectly achievable, as it is already a leader because they already lead in research in this area, and the United States is competing fiercely with them. However, the future of AI in the US has become unclear and declining due to state involvement, funding cuts, increased education costs and strict immigration restrictions for international research experts. The UK is a leader with more than $121 \mathrm{AI}$ companies as the country extensively funds and supports robotics and research in AI. Russia invests about $\$ 12.5$ million a year in AI. Germany is technically efficient, having the appropriate skills to implement and promote technological innovation and play a leading role in robotics. Norway launched accelerated investments in 2017 with $\$ 11$ million to develop technology hubs. The Swedish population shows $80 \%$ satisfaction with AI and robotics. In general, Sweden favours AI, believing it will improve human skills and competitive advantage in the global market. France will invest 1.8 billion USD alone and in partnership with Germany in AI research. India is a fast-growing country that has undergone many changes in its digital space and invested $8 \%$ of its GDP in 2017 to promote AI development (Sirvastava, 2019). Slovenia is also highly ambitious in the field of AI. In March 2020, the Government of the Republic of Slovenia signed an agreement with the United Nations Organization for Education and Culture (UNESCO) to establish the first international research centre for AI under the auspices of UNESCO, based in Ljubljana (Zorc, Lozej, and Blaznik, 2020, p. 7-8).

Lee (2019, p. 308-312) states that we increasingly feel AI around the world. The United States and China will lead the economically productive uses of AI, and all other countries will undoubtedly contribute to broader social development. Many of today's races for AI compared to the space race of the 1960s. Competition should focus on finding standard solutions to common problems. State authorities will have to pay attention at all times to new compromises on uncomfortable issues, data privacy, digital monopolies, online security and algorithm bias. 


\section{Businesses and the economy in the age of artificial intelligence}

Fast-growing European companies are increasingly leaving Europe in search of further growth that Europe is unable to deliver. No European Union's industrial policy can succeed without specific investments and measures in digitalisation, so we need a clear strategy of using the potential of platforms and data for SMEs in the digital age of growth. Digital technologies promote convergence between operational technologies and information technology. Industrial-style supply chains are transformed into value networks, where industrial companies combine and jointly develop technological solutions and increase the value of a service or product. Industrial platforms promote activities to meet their specific needs by connecting sellers, buyers, and other market players. These represent an opportunity and a challenge for Europe, especially in manufacturing the strategies for growth in the single market. The benefits of digitalisation will require an expanded product portfolio. Business-to-business cooperation is increasing. Large companies need to accelerate innovation processes, while small businesses are growing to carry out research and infrastructure shared by large companies. All this requires the European Union's investment policy, as innovation is the most effective way to increase industrial competitiveness. The European Union devotes at least $2 \%$ of GDP to research and development; on the other hand, America devotes about 2.8\% of GDP, Japan 3.2\% GDP, and South Korea $4.5 \%$ of GDP. Therefore, it is essential for Europe to publicly fund the AI research through Digital Europe, Horizon Europe, and other programmes to strengthen the digital technologies by promoting innovative solutions developed by partners from academia and industry (A stronger digital industrial Europe, 2020, p. 27-29).

Lee (2019, p. 234-236) states that China and American companies have a giant leap compared to the rest of the world. There is no shortage of top experts and research laboratories in Canada, Britain, France, and other countries. However, they often lack other ingredients needed by real AI superpowers (many users, an active ecosystem of entrepreneurs and venture capital). London's DeepMind (Which Way) and the World Health Protection Commission (AI) are the exceptions. The more data the AI leaders have obtained, the harder it will be for other companies seeking to compete with them, the more the top AI professionals come from the US and China. AI is involved in all aspects of the economy, with the US and China reaping significant gains in data and knowledge. At the same time, all of this generates a widening gap between those with $\mathrm{AI}$ and those without it.

Demir, Doven and Sezen $(2019$, p. 688) state that we are on the verge of the Fourth Industrial Revolution (Industry 4.0), representing smart manufacturing for the future. Industry 5.0 has a few visions, one of them being the collaboration between humans and robots. Industry 5.0 puts humans in the centre in a way to adapt AI technology to human guidelines. In recent years, we have seen significant advances in research into robotics and AI. Soon we will work closely with robots in our workplaces and our lives.

For ten years, industry 4.0 focused less on the original principles of social justice and sustainable development and more on digitalisation and AI. Industry 5.0 stresses the importance of research and innovation to support the industry in the long run to benefit humans and the planet on which we live. In a broader sense, industry 5.0 represents three cores: human focus, sustainability and resilience. In a global world, anything but the environment and social benefits takes into account profit. To ensure real prosperity for all, industry 5.0 must consider many factors, take responsibility for innovations aimed at increasing cost-effectiveness and increasing profits, and other stakeholders such as investors, workers, consumers, society and the environment. The starting point is not to study new technology but to increase the effectiveness of focusing on the human approach in the industry. What matters is what technology can do and do for humankind. The goal is to use technology to adapt production to the worker's needs, 
which means that we train and adjust it and run it accordingly. The use of new technologies must be without prejudice to the foundations of workers' rights, such as the right to privacy, autonomy and human dignity. Therefore, the fundamental task is to develop circular processes that reuse or recycle natural resources to reduce waste and environmental impact. AI can play a significant role in optimisation and efficiency in resource consumption and use and reducing waste. Geopolitical shifts and natural crises, such as the COVID-19 pandemic show us the fragility of the current approach. Globalised production needs to be balanced, and their capabilities adapted to serve basic human needs, such as healthcare and security. Industry 5.0 is an industry to achieve social goals leading to new jobs, growth and prosperity, where it puts workers at the heart of the manufacturing process (Breque, Nul, and Petridis, 2021 p. 13-15).

The proliferation of digital technologies has changed the entire world economy. The further expansion of digitisation calls for a significant improvement in the education and training of staff, highly skilled talent, who can carry out the digital development of the economy. Companies and employees need to be involved in designing and developing digital competencies among employees in manufacturing, as the management of digital competencies is very important for most professions (Sergeva, Reznik, Amirova, 2021, p. 1-6). Employees need to develop four essential competencies: communality, entrepreneurial mindset, communication and cooperation, and ethical intelligence. Employees who recognise the impact of their work on profitability feel more motivated to innovate if they contribute to their business results. Moral intelligence means that technology must be used responsibly by companies. Companies need to have processes that highlight ethical aspects, encourage open debate and recognise the impact of their innovation on the public domain. Companies need to create an environment where employees develop in-depth skills as part of their daily tasks (Marion, Fixson and Michelman, 2020).

\section{Ethical, human and moral values at the intersection with artificial intelligence}

Chance (Chance 2018, p. 31) says AI is all around us. People in the economy, at home and in development activities constantly work with AI systems without realising it. Hawking (Hawking 2018, p. 201-203) made it clear that AI would automate many processes in the midterm and bring well-being and equality to society. Super-intelligent AI could be some of the best or worst in the world because the danger is not in its abuse but in its abilities. Technology pioneers such as Bill Gates (Microsoft), Steve Wozniak (Apple) and Elon Musk (SpaceX, Tesla) have a similar view to Hawking. They are already highlighting the social implications and ethical issues of using AI. AI, in their opinion, has the potential to end hunger disease by developing and expanding its use. Together, they signed an open letter on AI, urging the profession to look at the social consequences seriously.

The incredible innovation sparked by the Fourth Industrial Revolution, from biotechnology to AI, redefines what it means to be human. As people and society, we will have to think about life extension, memory recovery, eradicating genetic diseases, etc. These innovations will raise one of the most significant ethical and moral, and religious issues we can face as human beings. The author wonders where technological advances are pushing us in the field of treatment, injury elimination, and parenting when talking about a better man who will be more intelligent, faster, and prettier. Similarly, complex are the issues relating to AI that thinks, predicts, decides for us. Amazon, Netflix and many others already have algorithms that predict which movies and books we might see or read, which websites to visit, suggest partners, and services in our neighbourhood. We would confide in a robotic doctor with a success rate of treatment of a human doctor. It also leads to philosophical questions in the digital age, how to preserve individuality, the origin of our diversity and democracy (Schwab 2018, p. 98-102). Lee (2019, p. 240-242) states that in the centuries after the Industrial Revolution, work was regarded as a 
source of earning for survival and a source of personal pride, identity, and meaning. When we introduce ourselves in a social environment, we often first represent our profession. The service fills our days, provides us with a pleasant routine and is a reliable source of interpersonal relationships. Regular pay is not only a reward for the work done, but it proves that we are a valued member of society who contributes to the joint project. The psychological consequences of unemployment caused by AI will be cut even more profoundly, constantly eliminating the economy. The question arises, what does it even mean to be human?

Trouth (2019), a Professor at the Massachusetts Institute of Technology, says in his article that $\mathrm{AI}$ is the greatest existential threat we know can take away our jobs and transform lives, but we still do not do enough. There are two possibilities for how AI will turn out. The first possibility is that AI will slowly take over every human discipline, which I know is working very well. After all, self-taught with exponentially growing computational power will be able to diagnose better than doctors, build houses better than human builders, and keep the economy better than economists. When we are all out of work, the machines will somehow destroy us because of some unpredictable programming, or we will become so dependent on devices that we will be slaves. Whether we know it or not, the machines will choose everything for us based on optimisation the best result. In medicine, verifiable statistics inform us of the best probability outcome, or we should not decide whether we would undertake a particular treatment. In politics, it would be devastating because machines will make political decisions for us in advance based on programmed bias, whether they were intended intentionally or not. There is another possibility, which means that we accept the existential threat of AI with the utmost seriousness, completely change our approach and start thinking about what is essential to human life. But if we do this, we can face the challenge of making AI that will enable all stakeholders to live a decent life. On that basis, we have to change our thinking from valuable to truly good, from blind belief inefficiency to a thoughtful understanding of what is best in human life. In this respect, AI machines have this critical flaw and have a statistical basis, so they cannot address what is best or unique. They can only tackle what is widespread enough for statistical analysis.

Europe can set an example for all countries in this regard, as it is one step ahead of everyone. In the European Report (European Commission, 2019), Europe is apparent in the Ethical Guidelines for Trusted Artificial Intelligence. On April 8, 2019, high-level AI experts presented ethical guidelines for trusted AI. They have prepared the publication of the first draft guidelines in December 2018, to which more than 500 comments were received through an open consultation. The guidelines set out seven essential requirements that AI systems must meet to be considered trustworthy.

- Human representation and control: AI systems should empower people, inform them to make decisions and promote their fundamental rights. At the same time, appropriate control mechanisms must be provided that can only be achieved through human approaches and confirmation.

- Technical strength and safety: AI systems must be resilient and safe. They must be secure, provide a backup plan if something goes wrong, be precise, reliable and reproducible. Only in this way can we ensure that unintended damage is also reduced and prevented.

- Privacy and data management: In addition to ensuring full respect for privacy and data protection, adequate data management mechanisms should be guaranteed, taking into account the quality and integrity of the data, and ensuring legitimate access to data. 
- Transparency: The data system and meth intelligence and business models must be transparent, which can also be achieved through traceability mechanisms. In addition, AI systems and their decisions must be interpreted tailored to the interested public. Finally, people need to be aware that they communicate with the AI system and be informed about system capabilities and limitations.

- Diversity, non-discrimination and justice: unfair prejudices must be avoided, as they could have more negative consequences, from marginalising vulnerable groups to prejudice and discrimination. AI systems that promote diversity should be accessible to all, regardless of disability, and be included in relevant stakeholders throughout the life cycle.

- Social and environmental prosperity: AI systems should benefit all people, including future generations. It is, therefore, necessary to ensure that they are sustainable and environmentally friendly. Also, they must consider the environment, including other living beings, and their social or social impact must be carefully studied.

Responsibility: mechanisms must be implemented to ensure accountability for AI systems and their results. Verifiability plays a crucial role in this, enabling the assessment of algorithms, data, and design processes in critical applications. Therefore, it is necessary to provide an appropriately accessible remedy.

\section{Discussion of research issues}

The research question RQ1 is How to reduce unemployment due to the spread of AI in society. We have to look at the problem more profound and more layered. All companies and companies introduce AI as aid, robotisation and automation as a substitute for human work, so simple jobs will be less and less, even global. The only option to secure employment is to learn, educate, and improve throughout our career years. Work is like a living organism always there, but it changes. We will never be afraid to work with continuous or all life education because different skills give us much more job opportunities. Therefore, we must have people in the education system and the leadership positions who are aware and help people and can encourage and motivate them to transform and adapt to the situation with the help of new skills before they lose their jobs. Curiosity, that skill is getting more and more undermining!

The research question of RQ2, who will take responsibility for the changes so that $\mathrm{AI}$ is trustworthy, should not allow the situation to unfold in a way that only guarantees a profit, return or growth at all costs. The European Union is one step ahead of other countries here, as is recognised by US experts, who are already inspired by the European Union's guidelines. The European Union will have to demonstrate and take responsibility through a robust and responsible policy - that man is the most critical part of society. Then, it can generate growth, profit, and progress to adapt AI to man and trust in AI, with different activities to all economies, institutions and private life. Those activities should be fully supported by the European Commission and governments, European Union member states. The European Commission must clearly define the same rules for all Member States and must not tolerate arbitrary decisions by the individual Member States.

\section{Conclusion}

AI represents invaluable assistance in jobs, at home and in leisure. In the past, technologies have not caused us permanent unemployment, and with the right approach, new technologies will not take jobs in the future. New jobs will be developed considering ethical, moral values 
and the guide that AI helps people achieve their tasks and goals. The professions will primarily be linked to digitalisation. There will be almost no areas where there is a need for skills and knowledge in information technologies related to AI. Europe is on track. It is the first to take AI seriously and define rules with industry 5.0 that allow AI to serve man and put it the centre. Regardless of the global race, global economies are unifying and exploiting the positive potential of AI in all areas.

The question is, what professions we are going to need in five, 10 or 20 years. Cooperation between people and AI, and economies underpinned by new technologies, will contribute to the development of new jobs to develop entirely new professions. The question is if we have enough knowledge to control all emerging processes in technologies and whether we can keep up with AI. We can improve all areas of the economy and the non-economy. Still, we need to be aware of the need for lifelong learning and training of employees, primarily in workplaces, threatened with extinction. New jobs will require digital skills, and urgent investment will be needed in transforming human resources and investing in education. Much attention will need to be paid to science, technology and science professions. The global development of AI and work will have to be based on safe and human moral-ethical rules by raising awareness of the negative and positive consequences and effects on humanity.

\section{References}

Alan Turing and the beginning of AI. Britannica encyclopaedia, Retrieved from https://www.britannica.com/technology/artificial-intelligence/Alan-Turing-and-the-beginning-of-AI

Breque, M., DeNul, L., \& Petridis, A. (2021). Industry 5.0 Towards a sustainable, human-centric and resilient European industry. Retrieved from https://op.europa.eu/en/publication-detail///publication/468a892a5097-11eb-b59f-01aa75ed71a1/

Chace, C. (2018). The economic singularity. Three Cs, p. 31

Demir, K., Doven, G., \& Sezen, B. (2019). Industri 5.0 and Human-Robot Co-working. Procedia Computer Science, Vol. 158, pp.688-695.

Digitaleurope. (2020). A stronger digital industrial Europe. Retrieved from https://www.digitaleurope.org/wp/wpcontent/uploads/2020/02/DigitalEurope-A-Stronger-Digital-Industrial-Europe.pdf

European Commission. (2019). Ethics guidelines for trustworthy AI. Retrieved from https://ec.europa.eu/digitalsingle-market/en/news/ethics-guidelines-trustworthy-ai

Fox, J. (2020). Towards a Canonical Theory of General Intelligence. Journal of Artificial General Intelligence, Vol. 11 No. 2, pp.35-40

Hawking, S. (2019). Short answers to fundamental questions. Učila International, p. 201

Lee, K.F. (2019). The superpowers of artificial intelligence. Ljubljana: National University Library, p. 204-242.

Minevich, M. (2020). Here's How Slovenia is shaping the new Human Centric Society and Pioneering the world in AI. Retrieved from https://www.forbes.com/sites/markminevich/2020/04/13/heres-how-slovenia-isshaping-the-new-human-centric-society-and-pioneering-the-world-in-ai/?sh=53c16d284860

Raiz Mir, U. Mahnaz Hassa, S., \& Majed Qadari, M. (2014). Understanding Globalisation and its Future: An Analysis. Pakistan Journal of Social Science. Retrieved from http://lcwu.edu.pk/ocd/cfiles/International\%20Relations/Min/IR-202-AC/PJSS-Vol34-No2-1811.pdf

Schwab, K. (2017). The Fourth Industrial Revolution. Penguin Random House UK, p. 98-102.

Sirvastava, S. (2019). Top 10 Countries Leading the Artificial Intelligence. Retrieved from https://www.analyticsinsight.net/top-10-countries-leading-the-artificial-intelligence-race/

Communication from the Commission to the European Parliament, the European Council, the European Social Committee and the Committee of the Regions. (2018). Artificial intelligence for Europe. Retrieved from https://eur-lex.europa.eu/legal-content/SL/TXT/PDF/?uri=CELEX:52018DC0237\&from=CS

Trout, B. (2019). Retrieved from https://shass.mit.edu/news/news-2019-ethics-and-ai-series-safeguardinghumanity-age-ai-bernhardt-trout

Zorc, S., Lozej, M., \& Blaznik, P. (2020). National Programme for the Promotion and Development and Use of Artificial Intelligence in the Republic of Slovenia by 2025. Retrieved from https://www.gov.si/assets/ministrstva/MJU/DID/NpAI_SI_2020-08-20_draft.pdf 